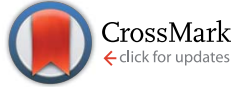

Cite this: RSC Adv., 2015, 5, 65953
Received 24th April 2015 Accepted 28th July 2015 DOI: $10.1039 / \mathrm{c} 5 \mathrm{ra0} 4443 f$

www.rsc.org/advances

\section{Sensitive and selective determination of aqueous triclosan based on gold nanoparticles on polyoxometalate/reduced graphene oxide nanohybrid}

\author{
Mehmet Lütfi Yola, ${ }^{a}$ Necip Atar, ${ }^{\text {b }}$ Tanju Eren, ${ }^{\mathrm{b}}$ Hassan Karimi-Maleh ${ }^{\mathrm{c}}$ \\ and Shaobin Wang*d
}

The widespread use of triclosan (TCS) in household cleaning products, medical devices and personal care poses a potential risk to the ecological system and human health due to its release into sediments, surface water and ground water resources and chronicle toxicity to aquatic organisms. A novel molecularimprinted electrochemical sensor based on gold nanoparticles decorating polyoxometalate $\left(\mathrm{H}_{3} \mathrm{PW}_{12} \mathrm{O}_{40}\right) /$ reduced graphene oxide was developed for determination of trace TCS in wastewater. Reduced graphene oxide ( $\mathrm{rGO}$ ) was functionalized by polyoxometalate (POM) through electrostatic interaction between the POM and rGO nanosheets to produce a photocatalyst (POM/rGO) in aqueous solution. Gold nanoparticles (AuNPs) were further deposited on the POM/rGO without using any reducing agent and the prepared nanomaterial (AuNPs/POM/rGO) was employed to modify a glass carbon (GC) electrode (AuNPs/POM/rGO/GC) under infrared light. Several techniques, X-ray photoelectron spectroscopy (XPS), reflection-absorption infrared spectroscopy (RAIRS), scanning electron microscopy (SEM), and transmission electron microscopy (TEM), were used for electrode characterization. TCS imprinted film was generated on AuNPs/POM/rGO/GC via polymerization of phenol and TCS and characterized by cyclic voltammetry (CV) and electrochemical impedance spectroscopy (EIS). The sensor was found to have a linear detection range and a limit of TCS at 0.5-50.0 $\mathrm{nM}$ and $0.15 \mathrm{nM}$, respectively. The molecular imprinted sensor was applied to wastewater and lakewater samples and demonstrated effective performance as compared to other complicated methods.

\section{Introduction}

TCS is a typical chemical that has been used in pharmaceuticals and personal products ${ }^{1}$ such as surgical suture materials or hand soaps, deodorants, toothpastes, antiseptic-creams, plastics, foodstuffs and functional clothing for over 40 years. ${ }^{2}$ Its widespread use has led to the release of TCS into wastewater, sediments and many water sources. ${ }^{3}$ TCS is chronically toxic to aquatic organisms and its presence in wastewaters may affect the ecosystem and human health. ${ }^{2}$ Several analytical methods have been reported to detect TCS using gas chromatography-tandem mass spectrometry, liquid chromatography-mass spectrometry (LC-MS), liquid chromatography/electrospray ionization tandem mass spectrometry and voltammetrics. ${ }^{4-10}$ But these techniques

${ }^{a}$ Department of Metallurgical and Materials Engineering, Sinop University, Sinop, Turkey

${ }^{b}$ Department of Chemical Engineering, Pamukkale University, Denizli, Turkey. E-mail: necipatar@gmail.com

${ }^{\circ}$ Department of Chemistry, Graduate University of Advanced Technology, Kerman, Iran ${ }^{d}$ Department of Chemical Engineering, Curtin University, GPO Box U1987, Perth, WA 6845, Australia.E-mail: shaobin.wang@curtin.edu.au have some disadvantages such as expensive apparatus and complicated operation. ${ }^{\mathbf{1 1 , 1 2}} \mathrm{A}$ rapid and sensitive method to detect triclosan is thus important to ensure human and environment safety. In recent years, various nanosensors have been reported for selective, sensitive and rapid determination of toxic compounds, biomolecules and drugs. ${ }^{\mathbf{1 2 - 1 5}}$

In the past few years, graphene has become an intensive interest of scientists all over the world due to its stability and high surface area. ${ }^{16,17}$ Graphene has honeycomb-like structure via $\mathrm{sp}^{2}$ hybridization in one-atom-thickness. ${ }^{18}$ Currently, graphene oxide (GO) is widely produced by chemical oxidation of graphite and used as a precursor to graphene. GO can be reduced by thermal treatment or chemical reduction to form $\mathrm{rGO},{ }^{19}$ and $\mathrm{rGO}$ has been used for fuel cells, drug detection and sensors. ${ }^{20-22}$ Many papers have also reported the chemical, ${ }^{23}$ optical, ${ }^{24}$ adsorption $^{25}$ and electronic properties ${ }^{26}$ of various nanostructured metals. AuNPs are utilized as electrode surface for sensors ${ }^{11,27}$ to increase the surface area and rate of electron transfer. In addition, polyoxometalates (POMs) are polyatomic anionic ion clusters composing of d-block transitional metal-oxides, and they have multiple redox behavior and photo-electrochemical properties. ${ }^{28,29}$ 
POMs are a class of photoactive materials used in homogeneous reactions or heterogeneous processes. In reduced forms, their electron and proton transfer and/or storage abilities make them act as efficient donors or acceptors of several electrons without structural change. POMs also have been shown to serve as reducing and capping agents for metal nanostructures. ${ }^{17}$ The molecular imprinting technique is widely used for molecular recognition ${ }^{30}$ via the polymerization of target molecules, forming specific cavities. ${ }^{24,27}$ From those above materials and molecular imprinting technique, various sensors can be fabricated.

There is no report about determination of TCS by using a molecular imprinting method based on the nanomaterials including rGO and AuNPs. Jiang et al. prepared AuNPs on GO surface by using polyethylenimine as a reducing reagent, followed by L-cysteine immobilization through an $\mathrm{Au}-\mathrm{S}$ bond. After the preparation, the nanocomposite was applied as a novel ZICHILIC material to achieve highly selective enrichment of glycopeptides from biological samples. ${ }^{31}$ In this study, AuNPs were synthesized under the UV light on rGO surface with POM as reducing and stabilizing reagent. We then prepared a TCS imprinted electrochemical sensor based on AuNPs deposition on POM functionalized rGO. The developed imprinted electrochemical sensor shows high sensitivity and selectivity in wastewater measurement.

\section{Experimental}

\subsection{Chemicals and materials}

TCS, methyltriclosan (MTC), triclocarban (TCC), $p$-chlorophenol (PCP) and 2,4,6-trichlorophenol (TCP) were purchased from Sigma-Aldrich (USA). A stock solution of TCS $(1.0 \mathrm{mM})$ was prepared in $5 \mathrm{~mL}$ of ultra pure water and then diluted to $25 \mathrm{~mL}$. The working solutions were then prepared with $0.10 \mathrm{M}$ phosphate buffer solution ( $\mathrm{pH}$ 7.0). Phenol, potassium ferricyanide $\left(\mathrm{K}_{3}\left[\mathrm{Fe}(\mathrm{CN})_{6}\right]\right)$, hydrogen tetra-chloroaurate hydrate $\left(\mathrm{HAuCl}_{4}\right)$, acetonitrile (MeCN), $\mathrm{H}_{3} \mathrm{PW}_{12} \mathrm{O}_{40}$, and isopropyl alcohol (IPA) were purchased from Sigma-Aldrich, USA. Potassium chloride $(\mathrm{KCl})$ and potassium ferrocyanide $\left(\mathrm{K}_{4}\left[\mathrm{Fe}(\mathrm{CN})_{6}\right]\right)$ in analytic grade were supplied by Merck, Germany.

\subsection{Instrumentation}

Differential pulse voltammetry (DPV) and CV were carried out on an electrochemical station (IviumStat, US) equipped with a C3 cell stand. Electrochemical impedance spectroscopy (EIS) data were acquired at $10 \mathrm{mV}$ wave amplitude from 0.1 to 100 $\mathrm{kHz}$ and at an electrode potential of $0.195 \mathrm{~V}$. The infrared spectra were obtained from a Bruker Tensor 27 FT-IR. XPS analysis was performed on a PHI 5000 Versa Probe X-ray photoelectron spectrometer ( $\Phi$ ULVAC-PHI, Inc., Japan/USA). TEM images were obtained on a JEOL 2100 HRTEM instrument (JEOL Ltd, Tokyo, Japan) and SEM images were obtained on a ZEISS EVO 50 analytic microscope (Germany).

\subsection{Cleaning of glass carbon (GC) electrodes}

All GC electrodes were first polished by 0.1 and $0.05 \mu \mathrm{m}$ alumina successively and then the electrodes were sonicated in pure water and IPA $+\mathrm{MeCN}$ solution (50:50 by v/v) to remove unreacted materials from the surface. The reference electrode was a $\mathrm{Ag} / \mathrm{AgCl} / \mathrm{KCl}_{(\text {sat })}$ and the counter electrode was a Pt wire.

\subsection{Preparation of rGO}

GO was prepared according to the protocol in our previous papers. ${ }^{14}$ The as-prepared GO was dispersed into water $(200 \mathrm{~mL})$ with addition of hydrazine hydrate $(4 \mathrm{~mL}, 80 \mathrm{wt} \%)$ and was heated at $100{ }^{\circ} \mathrm{C}$ for $24 \mathrm{~h}$ in an oil bath. The rGO was collected by vacuum filtration.

\subsection{Fabrication of AuNPs on POM/rGO and preparation of AuNPs/POM/rGO/GC}

The as-synthesized rGO was dissolved in an ethanol solution (2 $\mathrm{mg} \mathrm{mL}{ }^{-1}$ ) for $1 \mathrm{~h}$ ultrasonic agitation. $\mathrm{A}_{3} \mathrm{PW}_{12} \mathrm{O}_{40}$ solution ( 1 $\mathrm{mL}, 1 \mathrm{mM}$ ) was reduced using a ultra-violet (UV) light source. The rGO suspension was then well mixed with the reduced POM at a $1: 1(0.5: 0.5$ by v/v) volume ratio for $2 \mathrm{~h}$ to get POM/rGO. A $\mathrm{HAuCl}_{4}$ solution $(1 \mathrm{mM})$ was added to the POM/rGO solution $\left(0.4 \mathrm{mg} \mathrm{mL} \mathrm{mL}^{-1}\right)$ at a $1: 1(2.0: 2.0$ by $\mathrm{v} / \mathrm{v})$ volume ratio. The solution was sonicated to form a homogeneous suspension. The prepared solution was stirred under the UV light for $40 \mathrm{~min}$. Finally, $20 \mu \mathrm{L}$ of AuNPs/POM/rGO (0.5 mg mL $\left.{ }^{-1}\right)$ was dropped on the GC electrode and then the modified electrode (AuNPs/ $\mathrm{POM} / \mathrm{rGO} / \mathrm{GC}$ ) was dried under an infrared heat lamp.

\subsection{Preparation of imprinted TCS sensors}

The preparation of TCS imprinted sensors is illustrated in Scheme 1. Firstly, TCS molecular imprinted polymer (MIP) film on AuNPs/POM/rGO/GC electrode (MIP/AuNPs/POM/rGO/GC) was prepared by $\mathrm{CV}$ for 20 cycles using $80 \mathrm{mM}$ phenol as a monomer in a phosphate buffer solution ( $\mathrm{pH}$ 7.0) containing 20 $\mathrm{mM}$ TCS at a scan rate of $100 \mathrm{mV} \mathrm{s}^{-1}$ between $0.0 \mathrm{~V}$ and $+1.0 \mathrm{~V}$. After electropolymerization, the electrode was dried at room temperature. For comparison, MIP/GC, MIP/rGO/GC and MIP/ $\mathrm{POM} / \mathrm{rGO} / \mathrm{GC}$ electrodes were also prepared with same way. A non-polymer imprinted electrode (NIP) was prepared without using TCS for a control experiment like the preparation of MIP. To break up the electrostatic interactions between phenol monomer and polar groups of the TCS, we used $1.0 \mathrm{M} \mathrm{NaCl}$ as desorption agent in a batch system. A TCS imprinted electrode was dipped into $25 \mathrm{~mL}$ of the $1.0 \mathrm{M} \mathrm{NaCl}$ aqueous solution and was swung in a bath $(200 \mathrm{rpm})$ at room temperature for $20 \mathrm{~min}$. After that, the electrode was washed with ultra pure water and dried in nitrogen gas under vacuum $\left(200 \mathrm{mmHg}, 25^{\circ} \mathrm{C}\right)$. The MIP electrodes were stored in a closed box without fluctuations of temperature and pressure. In addition, the voltammograms were obtained in an insulation cabinet for avoiding temperature and pressure fluctuation to affect the sensor response.

\subsection{Preparation of wastewater samples}

Wastewater samples were collected from an industrial wastewater pool in Izmir, Turkey, using pre-cleaned amber glass bottles. Lakewater samples were collected from Van Lake in Turkey. The sample bottles were filled without headspace and 


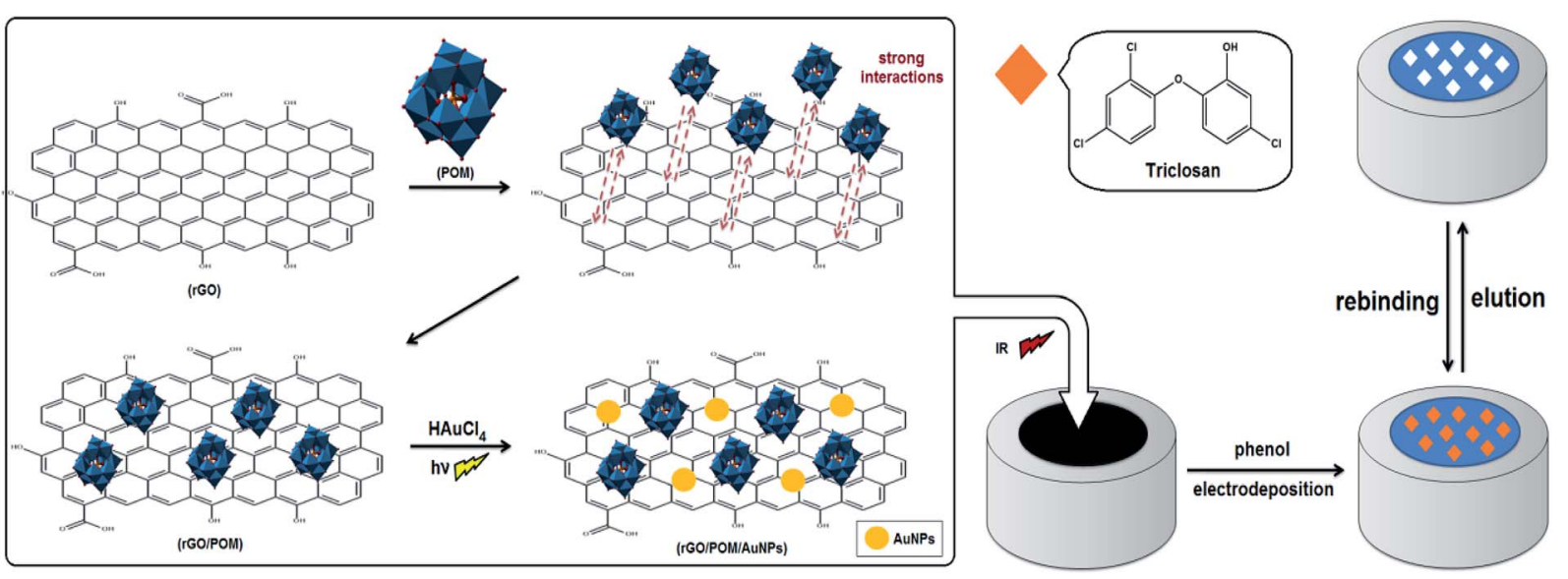

Scheme 1 Fabrication procedure of the MIP/AuNPs/POM/rGO/GC sensor.

immediately placed in coolers filled with icepacks and transferred to the laboratory for storage at $4{ }^{\circ} \mathrm{C}$ and analysis within one week. Before analysis, the collected wastewater and lakewater samples were centrifuged again at $4500 \mathrm{rpm}$ for $5 \mathrm{~min}$ and filtrated by a $0.45 \mu \mathrm{m}$ syringe filter. The filtrates were then diluted with $0.1 \mathrm{M}$ phosphate buffer solution $(\mathrm{pH}$ 7.0) for analysis.

\section{Results and discussion}

\subsection{Characterization of electrode surface}

TEM image of AuNPs/POM/rGO shows that the particle sizes of AuNPs are very similar at the mean diameter of 8-9 nm (Fig. 1A). The AuNPs are presented in dark dots on a lighter-shaded substrate of planar POM/rGO sheets. The creased nature of rGO is highly beneficial in providing a high surface area on GC electrodes. In addition, $\mathrm{C}, \mathrm{Au}, \mathrm{O}, \mathrm{W}$ and $\mathrm{P}$ peaks have been observed in EDX analysis (Fig. 1B), confirming the formation of AuNPs/POM/rGO nanohybrid. The IR spectra of the AuNPs/ $\mathrm{POM} / \mathrm{rGO}$ also show the formation of the nanohybrid (Fig. 1C). The bands around $3200 \mathrm{~cm}^{-1}$ and $1600 \mathrm{~cm}^{-1}$ suggested the oxygen-containing functional groups of rGO. The peaks around $1580 \mathrm{~cm}^{-1}$ can be attributed to the stretching vibrations of $\mathrm{C}=\mathrm{O}$ groups of the $\mathrm{rGO}$ sheets. Fig. $1 \mathrm{C}$ confirms the POM attached on rGO planes. The bands around $1050 \mathrm{~cm}^{-1}$ and $1350 \mathrm{~cm}^{-1}$ are referred to metal-oxygen groups of POM/ rGO. The formation of POM/rGO may be explained with the electrostatic interaction between POM and rGO via strong adsorption. ${ }^{28,32}$ The formation of AuNPs/POM/rGO was further examined by XPS. The peaks of $\mathrm{C}_{1 \mathrm{~s}}, \mathrm{P}_{2 \mathrm{p}}, \mathrm{Au}_{4 \mathrm{f}}$ and $\mathrm{W}_{4 \mathrm{f}}$ confirmed the formation of AuNPs/POM/rGO nanohybrid (Fig. 1D). The $\mathrm{Au}_{4 \mathrm{f}}{ }^{7 / 2}$ peak at $82.5 \mathrm{eV}$ confirms the presence of AuNPs and the signal at $87.2 \mathrm{eV}$ can be attributed to free gold nanoparticles. ${ }^{14}$

SEM characterization was performed to evaluate the morphologies of the electrode surfaces in step by step modification. Fig. 2A displays that GC electrode has smooth surface. Fig. 2B shows the layers of rGO indicating high surface area of modified GC surface while Fig. $2 \mathrm{C}$ presents the $\mathrm{POM} / \mathrm{rGO} / \mathrm{GC}$ electrode surface. For AuNPs/POM/rGO on GC electrode, an intensive layer was observed covering the surface (Fig. 2D). An electrodeposition layer by electro polymerization of phenol covered the MIP/AuNPs/POM/rGO/GC electrode. These images indicate that the imprinted electrochemical sensor is accomplished (Fig. 2E). Moreover, AuNPs/POM/rGO/GC was regular spheres while the surface was rough. Compared with $\mathrm{POM} / \mathrm{rGO} /$ GC, the existence of AuNPs could not only enhance the adsorption capacity but also conducive to the formation of MIP/ AuNPs/POM/rGO/GC, playing the role of a framework for the formation of $\mathrm{MIP} / \mathrm{AuNPs} / \mathrm{POM} / \mathrm{rGO} / \mathrm{GC}$. Some granular substances were attached on the surface of MIP/AuNPs/POM/ $\mathrm{rGO} / \mathrm{GC}$, indicating the formation of MIPs through electrochemical polymerization.

Electro polymerization was performed by $\mathrm{CV}$ in a phosphate buffer solution $(0.1 \mathrm{M}, \mathrm{pH} 7.0)$ and the voltammograms are presented in Fig. 3. It was clearly demonstrated that the currents decreased with number of the cycles. The oxidation of phenol was recorded as the irreversible peak at the potential of $0.65 \mathrm{~V}$ on the first scan. During continuous scanning, the current of the reduction peak decreased and then disappeared. This showed MIP film formation on the AuNPs/POM/rGO/GC electrode.

\subsection{Characterization of electrode impedance}

EIS of bare GC electrode displays a small semicircle at high frequencies. The value of charge transfer resistance $\left(R_{\mathrm{ct}}\right)$ of the bare GC electrode was calculated to be $100 \mathrm{ohm}$ (curve a of Fig. 4A). When the rGO was coating on the bare GC electrode, the value of $R_{\mathrm{ct}}$ was calculated as $70 \mathrm{ohm}$ (curve b of Fig. 4A). This is clearly indicative that the rGO layer increases the electron transfer rate. When the POM was coating on $\mathrm{rGO} / \mathrm{GC}$ electrode, the value of $R_{\mathrm{ct}}$ was found to be $58 \mathrm{ohm}$ (curve c of Fig. 4A). These performances were attributed to the large surface area and the synergistic effect of POM and rGO. The EIS of AuNPs/POM/rGO/GC electrode presents in a straight line, the characteristic of a diffusional limiting step (curve d of Fig. 4A). Hence, it is clear that AuNPs/POM/rGO nanocomposite 
A)
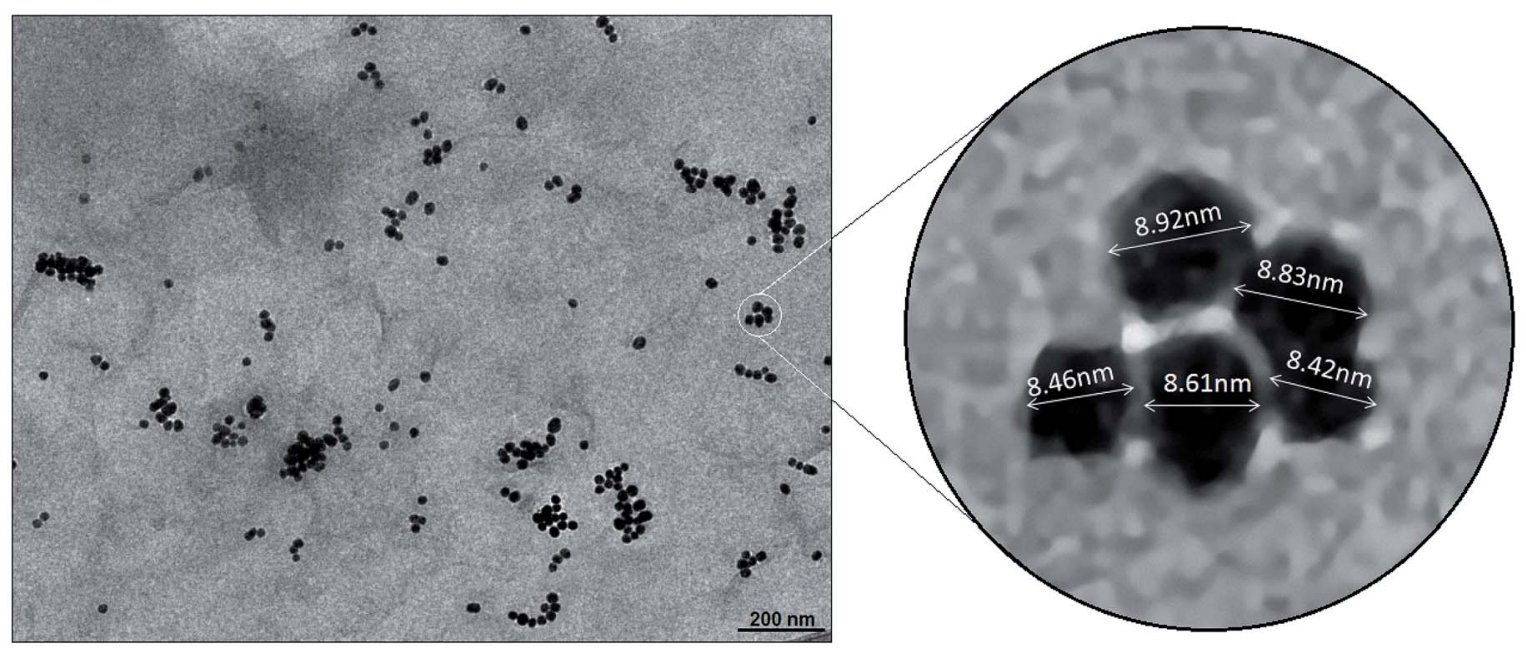

B)
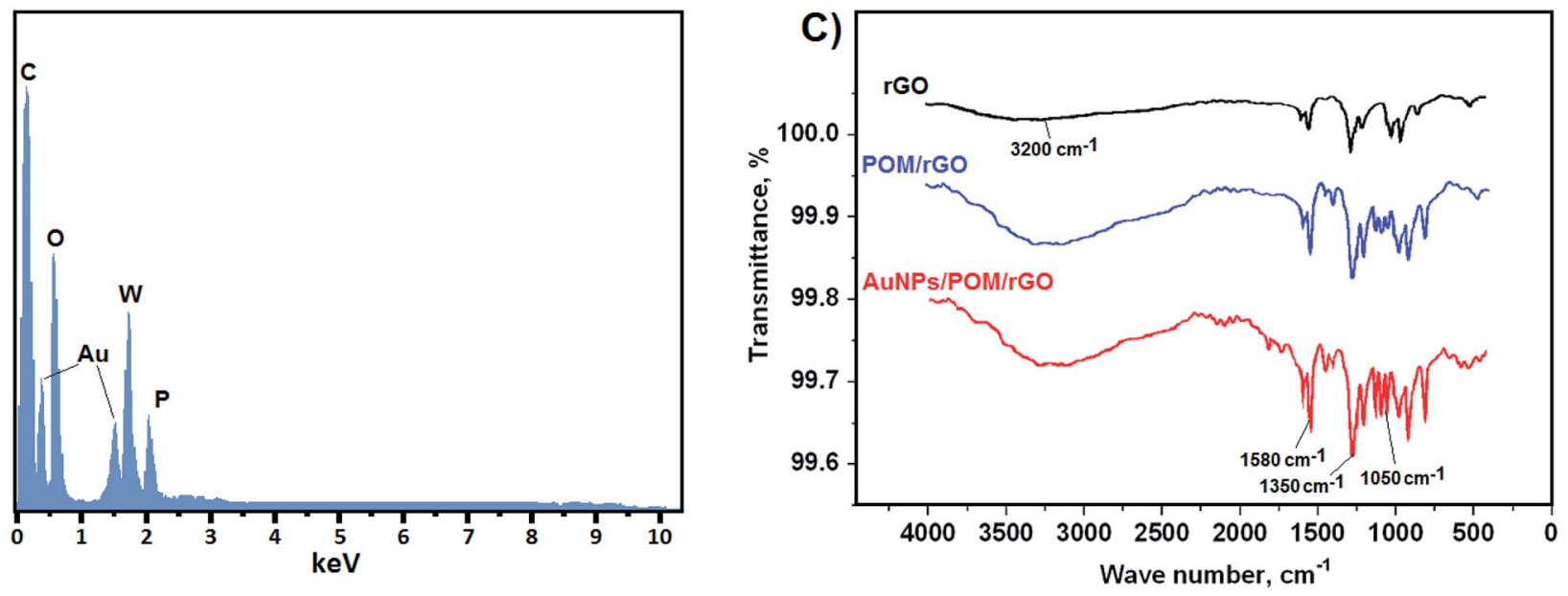
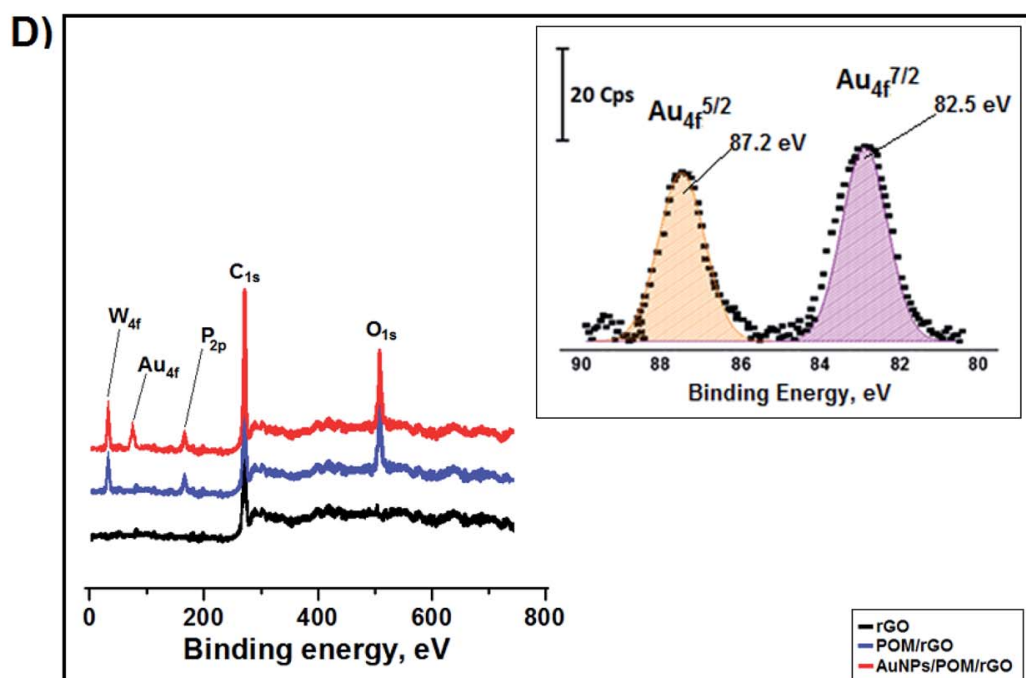

Fig. 1 (A) TEM image of the AuNPs/POM/rGO, (B) EDX analysis of AuNPs/POM/rGO, (C) RAIRS spectra of rGO, POM/rGO and AuNPs/POM/rGO, (D) XPS spectra of AuNPs/POM/rGO surface.

effectively increased the electrode active area. Because AuNPs/ $\mathrm{POM} / \mathrm{rGO}$ nanocomposite has such a large surface area and the synergistic effect, it improved electro-oxidation of $1.0 \mathrm{mM}$ $\left[\mathrm{Fe}(\mathrm{CN})_{6}\right]^{3-/ 4-}$ solution in $0.1 \mathrm{M} \mathrm{KCl}$. Hence, this nanocomposite facilitated the electron transfer and electrooxidation of TCS.

In addition, after the electrochemical polymerization of phenol monomer on AuNPs/POM/rGO/GC electrode, the MIP/ 

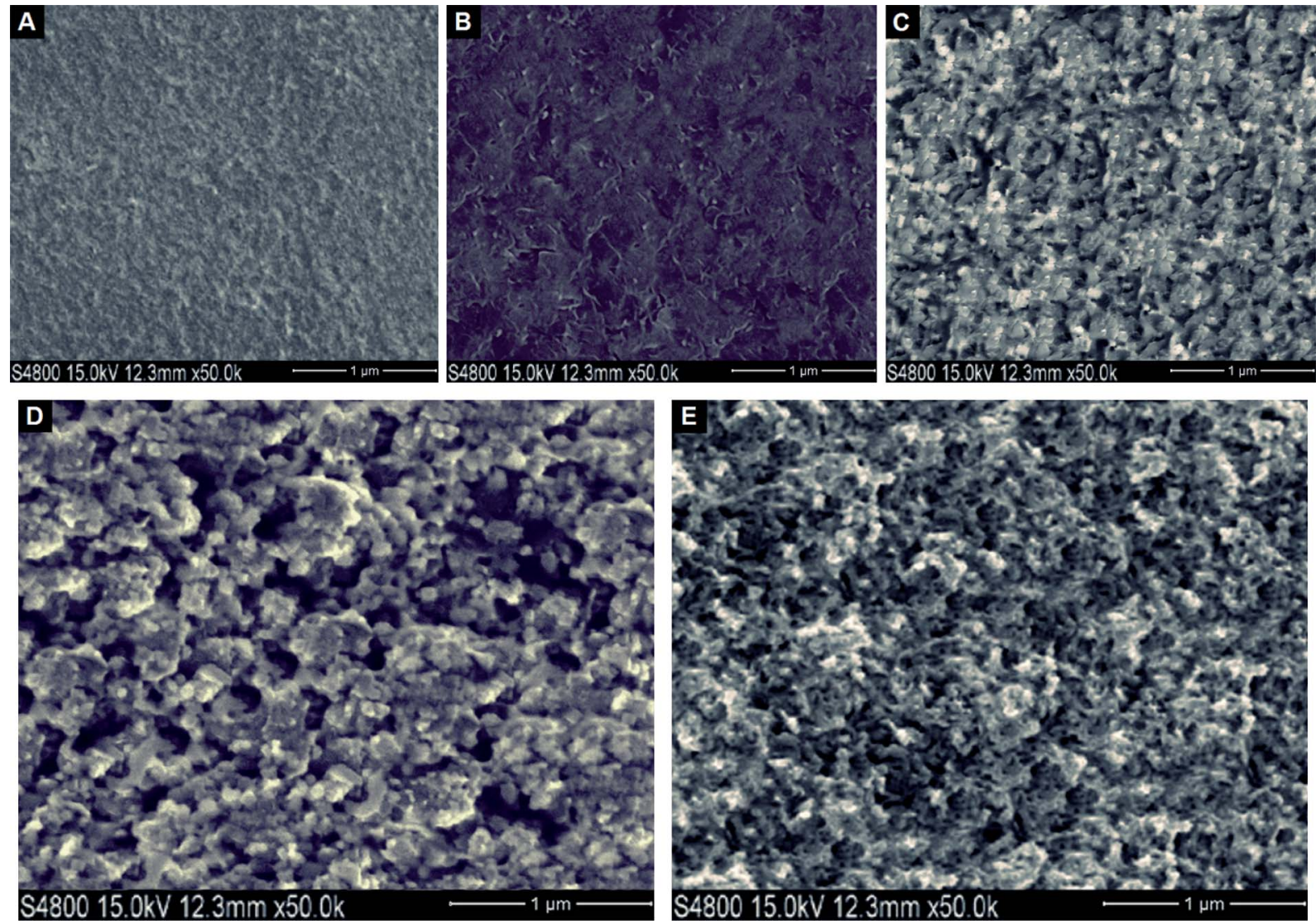

Fig. 2 SEM images of bare GC (A), rGO/GC (B), POM/rGO/GC (C), AuNPs/POM/rGO/GC (D) and MIP/AuNPs/POM/rGO/GC (E) surfaces

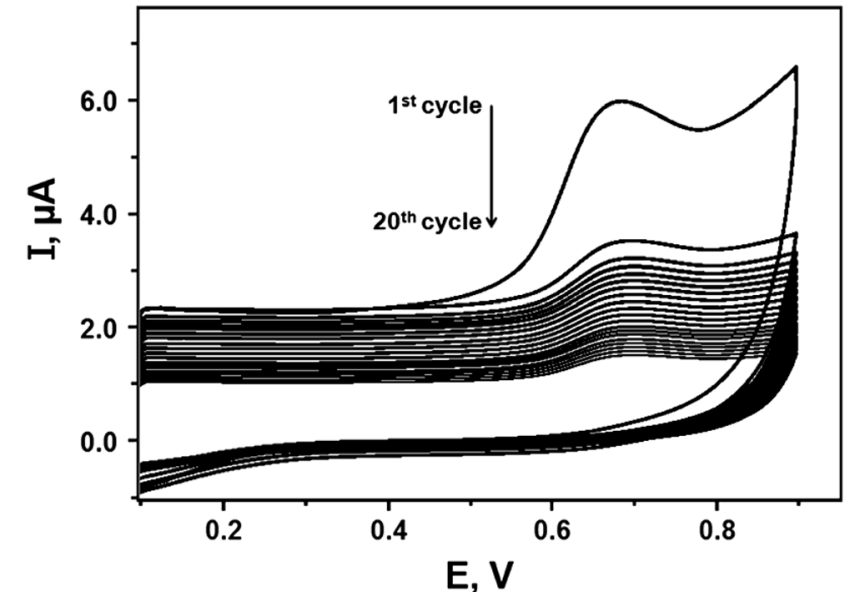

Fig. 3 Cyclic voltammogram for the electrochemical polymerization of phenol with TCS in phosphate buffer solution. Phenol $(80 \mathrm{mM})$, TCS (20 mM), pH 7.0, and scan rate of $100 \mathrm{mV} \mathrm{s}^{-1}$ for 20 cycles.

AuNPs/POM/rGO/GC electrode shows a large $R_{\mathrm{ct}}(610 \mathrm{ohm})$ (curve b of Fig. 4B), indicating that the MIP film displays a strong obstruction effect. After removal of TCS molecules from the electrode surface, the recognition sites appear and the $R_{\mathrm{ct}}$ decreases to about $270 \mathrm{ohm}$ (curve c of Fig. 4B). After rebinding of TCS $(10.0 \mathrm{nM})$, the $R_{\text {ct }}$ increases to $410 \mathrm{ohm}$ (curve d of
Fig. 4B), demonstrating that TCS adsorption can prevent the electrochemical activity of $1.0 \mathrm{mM}\left[\mathrm{Fe}(\mathrm{CN})_{6}\right]^{3-/ 4-}$.

\subsection{Characterization of voltammetrics of electrodes}

DPV showed the responses of TCS at different electrodes (Fig. 4C and D). The MIP/AuNPs/POM/rGO/GC electrode shows no background current signal in $0.1 \mathrm{M}$ phosphate buffer $(\mathrm{pH}$ 7.0) (curve a of Fig. 4C). After rebinding of TCS (10.0 nM TCS), it shows a much higher peak at about $0.65 \mathrm{~V}$ (curve $\mathrm{c}$ of Fig. 4C). However, the NIP/AuNPs/POM/rGO/GC electrode shows a small current signal (curve b of Fig. 4C). This indicates that the nonspecific interaction of TCS is weak and the response after MIP is very strong. The performances of different MIP sensors were also compared by DPV (Fig. 4D). It is shown that the performance of MIP/AuNPs/POM/rGO/GC electrode (curve $\mathrm{d}$ of Fig. $4 \mathrm{D}$ ) is better than that of $\mathrm{MIP} / \mathrm{POM} / \mathrm{rGO} / \mathrm{GC}, \mathrm{MIP} / \mathrm{rGO} / \mathrm{GC}$ and MIP/GC electrodes (curves c, b and a of Fig. 4D) due to more effective surface area.

\subsection{Optimization of fabrication and analytical conditions}

The effects of the concentration of AuNPs/POM/rGO on MIP/ AuNPs/POM/rGO/GC electrode were first tested. Initially, with the increasing concentration of AuNPs/POM/rGO up to $0.5 \mathrm{mg}$ $\mathrm{mL}^{-1}$, the peak current of TCS increased and reached a maximum at $7 \mu \mathrm{A}$. However, after the concentration exceeded 

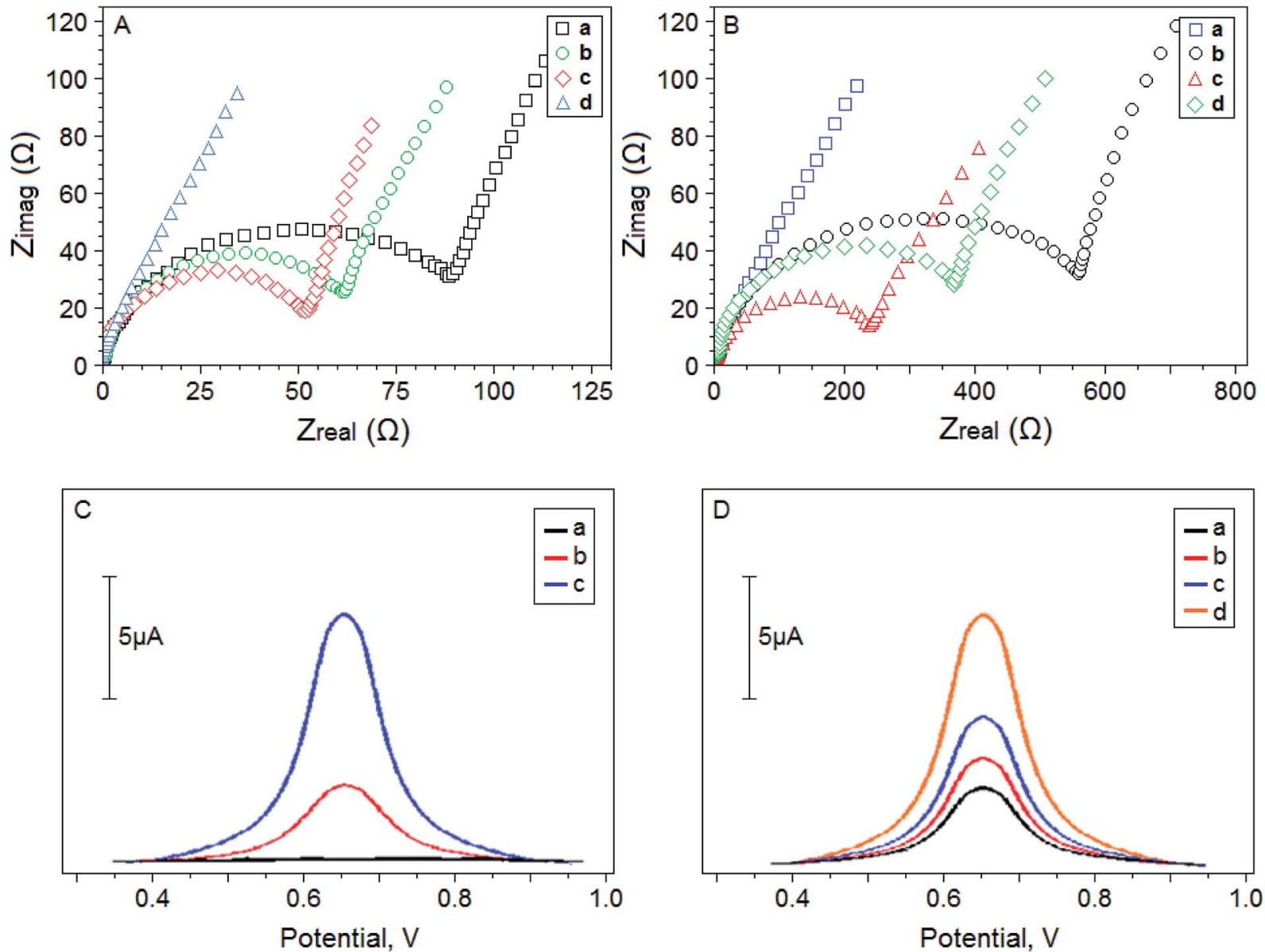

Fig. 4 (A) EIS of (a) bare GC; (b) rGO/GC; (c) POM/rGO/GC; (d) AuNPs/POM/rGO/GC electrodes in $1.0 \mathrm{mM}$ [Fe(CN)6] ${ }^{3-/ 4-}$ solution in 0.1 M KCl, (B) EIS of (a) AuNPs/POM/rGO/GC; (b) MIP/AuNPs/POM/rGO/GC (with template molecule); (c) MIP/AuNPs/POM/rGO/GC (removing template); (d) after rebinding of TCS $(10.0 \mathrm{nM})$ in $1.0 \mathrm{mM}\left[\mathrm{Fe}(\mathrm{CN})_{6}\right]^{3-14-}$ solution in $0.1 \mathrm{M} \mathrm{KCl}$, (C) DPVs of different electrodes in $0.1 \mathrm{M}$ phosphate buffer (pH 7.0) (a) MIP/AuNPs/POM/rGO/GC in blank buffer solution, (b) NIP/AuNPs/POM/rG/GC after rebinding of $10.0 \mathrm{nM}$ TCS, (c) MIP/AuNPs/POM/rGO/ GC after rebinding of $10.0 \mathrm{nM} \mathrm{TCS}$, (D) DPV curves of different MIP electrodes in $0.1 \mathrm{M}$ phosphate buffer (pH 7.0) after rebinding of $10.0 \mathrm{nM}$ TCS (a) GC; (b) rGO/GC; (c) POM/rGO/GC; (d) AuNPs/POM/rGO/GC electrodes.

$0.5 \mathrm{mg} \mathrm{mL}{ }^{-1}$, the peak current of TCS $(10.0 \mathrm{nM})$ is decreased (Fig. 5A). Hence, $0.5 \mathrm{mg} \mathrm{mL}{ }^{-1}$ of AuNPs/POM/rGO was selected as the optimum amount.

The $\mathrm{pH}$ of the medium also produces a significant influence on the polymeric film. ${ }^{11,14} \mathrm{Fig}$. $5 \mathrm{~B}$ demonstrates the DPV peak current in the $\mathrm{pH}$ range of 5.0-9.0. The maximum signal was appearing at $\mathrm{pH}$ 7.0. TCS molecules show different electrochemical oxidation behaviors to the polymeric film at different pHs. The DPV response of TCS increased with solution $\mathrm{pH}$ up to 7.0 and decreased subsequently. After the solution $\mathrm{pH}$ exceeded 7.0, the decrease of the peak current may be owing to the dissociation of the phenolic moiety.

The influence of TCS to phenol monomer molar ratio was also studied (Fig. 5C). The peak current of TCS achieved a maximum at the ratio of $1: 4$. This was linked with the available binding sites. At low amount of phenol monomer, the available binding sites were less. According to the results, the signal of TCS increased when the amount of monomer increased to $80.0 \mathrm{mM}$. The increase was resulted from increase of the number of binding site. However, at a high concentration of phenol monomer, the non-specific interactions of TCS-monomer could occur, reducing the specific response.

Fig. 5D shows the variation of DPV responses at different elution time. The TCS peak current shows increasing with the elution time, reaching a maximum at $20 \mathrm{~min}$, and then it remained stable after $20 \mathrm{~min}$, indicating that the elution of TCS was completed during $20 \mathrm{~min}$. Thus, the optimal elution time at 20 min was taken.

Fig. 5E shows the effect of temperature on DPV responses in the range of $5-30{ }^{\circ} \mathrm{C}$. As shown in Fig. $5 \mathrm{E}$, the highest peak current occurred at $20{ }^{\circ} \mathrm{C}$. After that, it remained stable. Therefore, the experiment temperature was chosen as $20^{\circ} \mathrm{C}$.

\subsection{The linear detection range of TCS}

The differential pulse voltammograms at varying TCS concentrations (Fig. 6A) show that the peak currents increased with 


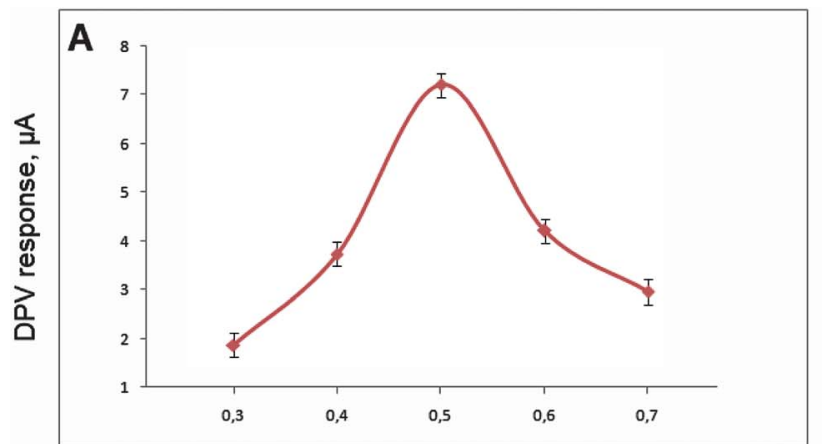

The concentration of AuNPs/POM/rGO, $\mathrm{mg} \mathrm{mL}^{-1}$

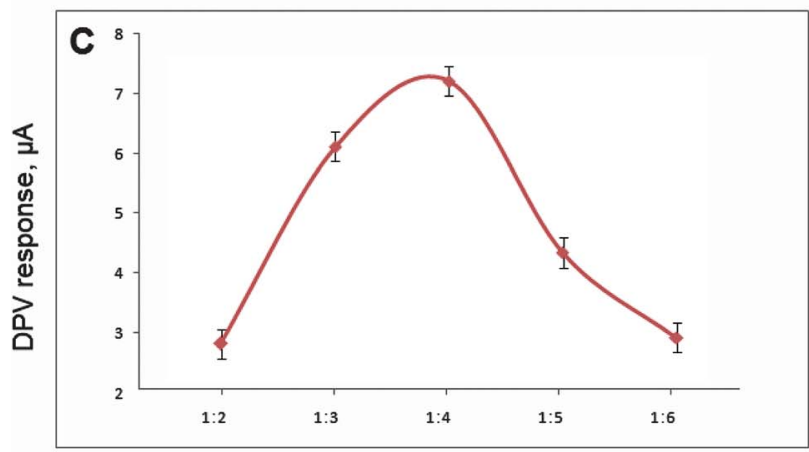

Mole ratio of TCS molecule to phenol monomer

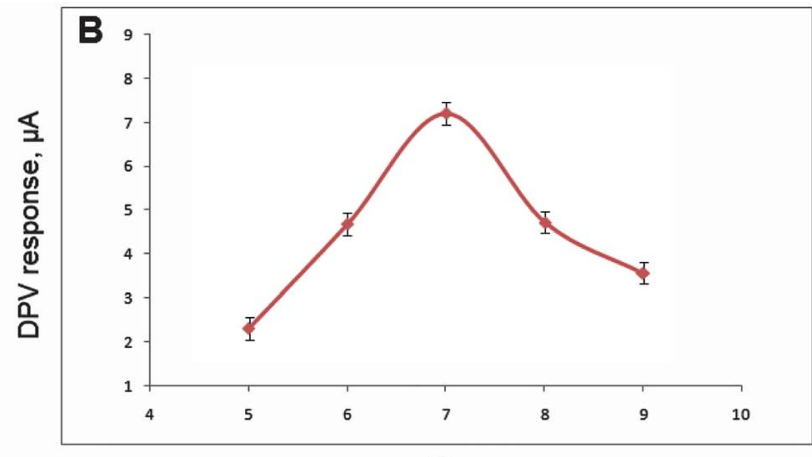

$\mathrm{pH}$

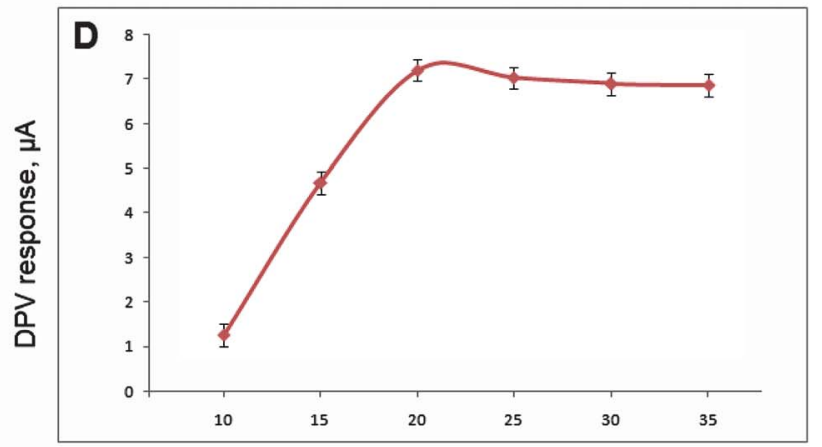

Elution Time, min.

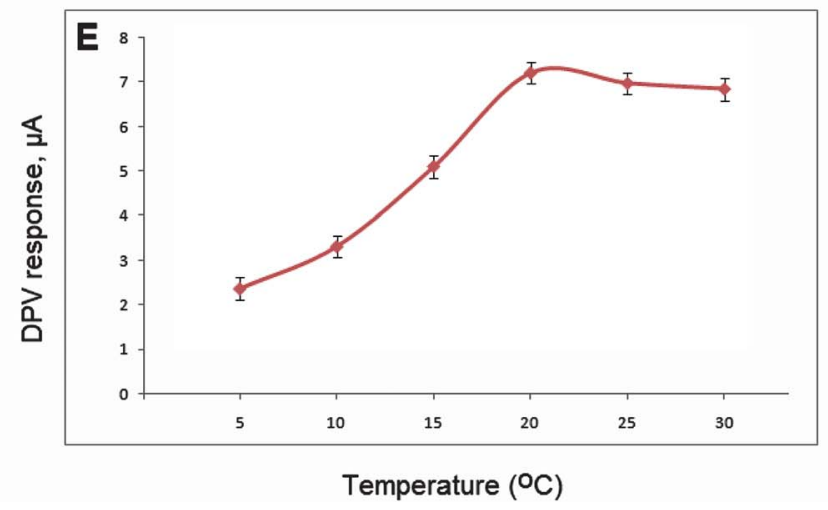

Fig. 5 Effects of the concentration of AuNPs/POM/rGO (A), pH (B), molar ratio TCS molecule to phenol monomer (C), elution time (D) and temperature (E).

increasing TCS concentration. For each point of the calibration graph, six independent measurements were obtained and the mean value was used. The linear regression equation of TCS (Fig. 6B) was obtained as $y=0.471 x+1.593$. From the equation, limits of TCS quantification (LOQ) and its detection (LOD) were found to be $5.0 \times 10^{-10} \mathrm{M}$ and $1.5 \times 10^{-10} \mathrm{M}$, respectively. ${ }^{27}$

Moreover, the recovery experiments in wastewater and lakewater samples were conducted using different TCS concentrations (Table 1). The recovery rate of $98.9-100 \%$ shows excellent recovery of the developed TCS imprinted electrochemical sensor. For a comparison, LC-MS as a sensitive method was further performed ${ }^{14}$ and no significant difference between the LC-MS and DPV was found based on the Wilcoxon test $\left(T_{\text {calculated }}>T_{\text {tabulated }}, p>0.05\right)($ Table 2$)$.
3.6. Reproducibility, stability and selectivity of the MIP/ AuNPs/POM/rGO/GC sensors

For the sensor, TCS selectivity was investigated by detection of other chemicals with the similar structure, TCC, MTC, PCP and TCP. TCS imprinted sensor presents 5.0, 6.6, 9.0 and 18.0 times as high as the signal for TCC, MTC, PCP and TCP, respectively (Fig. 7A and B), indicating its good selectivity. The interference values of TCC, MTC, PCP and TCP are $22.0 \%, 15.1 \%, 11.1 \%$ and $5.5 \%$, respectively. In addition, the developed MIP sensor was applied to blank solution, $15.0 \mathrm{nM}$ standard TCS and wastewater sample containing $15.0 \mathrm{nM}$ TCS to investigate matrix effect. The voltammogram obtained from wastewater sample containing $15.0 \mathrm{nM}$ TCS was identical with the voltammogram obtained from standard solution containing an equivalent of 


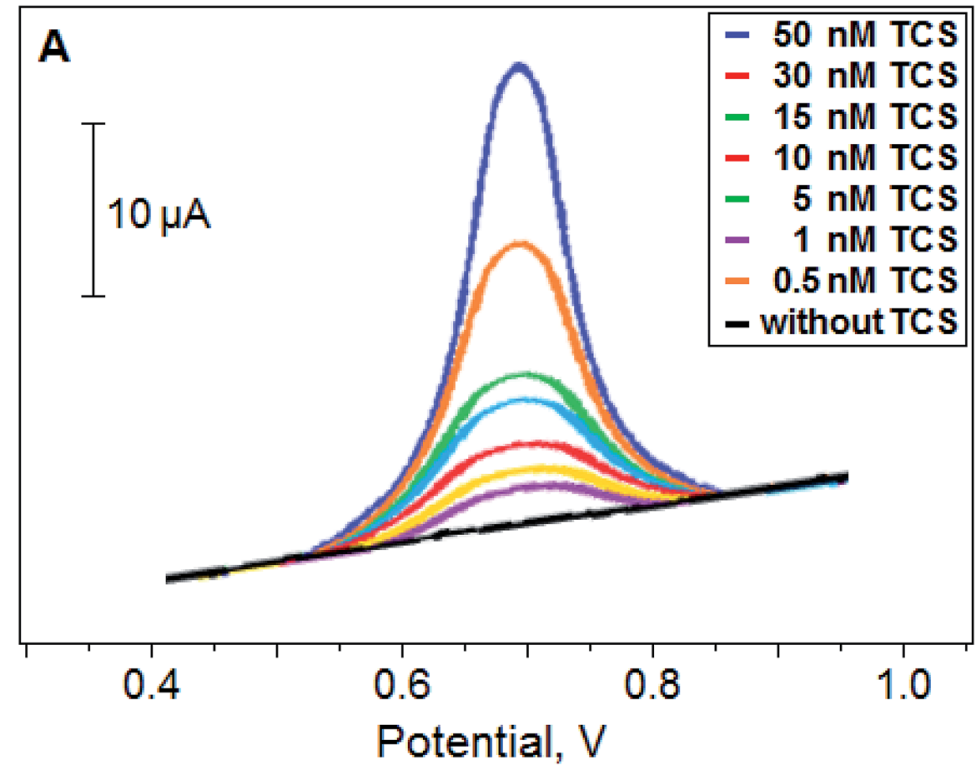

B

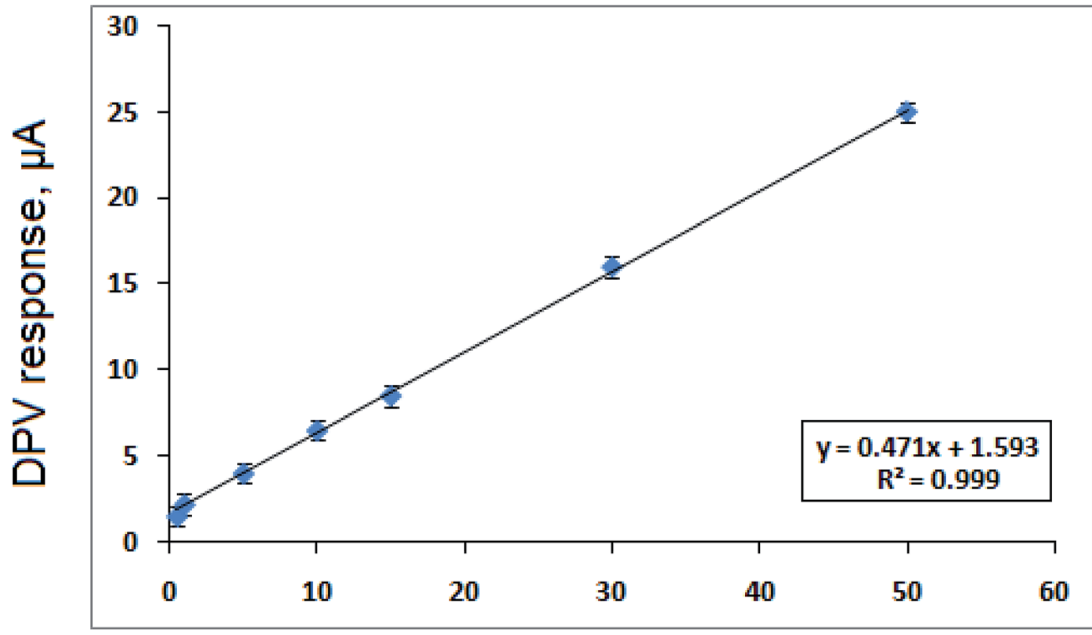

TCS Concentration, $\mathrm{nM}$

Fig. 6 DPV profiles of the electrochemical sensor at different TCS concentrations in phosphate solution pH 7.0 from background without TCS to $50.0 \mathrm{nM}$ TCS (A), and linear calibration curve of TCS (B).

Table 1 The TCS recoveries in wastewater and lakewater samples $(n=6)$

\begin{tabular}{llll}
\hline Sample & Added TCS (nM) & Found TCS (nM) & Recovery (\%) \\
\hline \multirow{2}{*}{ Wastewater } & - & $3.10 \pm 0.03$ & - \\
& 3.0 & $6.03 \pm 0.02$ & $98.9 \pm 0.5$ \\
& 6.0 & $9.02 \pm 0.04$ & $99.1 \pm 0.4$ \\
Lakewater & 9.0 & $12.1 \pm 0.02$ & $99.8 \pm 0.2$ \\
& - & $1.66 \pm 0.06$ & - \\
& 6.0 & $4.65 \pm 0.04$ & $99.8 \pm 0.6$ \\
& 9.0 & $9.67 \pm 0.02$ & $100.1 \pm 0.2$ \\
& & $10.6 \pm 0.05$ & $99.8 \pm 0.3$
\end{tabular}

Table 2 Comparison of the analytic results from DPV and LC-MS methods in determination of TCS $(n=6)(\text { added TCS }=6.0 \mathrm{nM})^{a}$

\begin{tabular}{lll}
\hline & \multicolumn{2}{l}{ Found TCS } \\
\cline { 2 - 3 } Sample & DPV & LC-MS \\
\hline Wastewater $(\mathrm{nM})$ & $9.02 \pm 0.04$ & $8.95 \pm 0.04$ \\
SD & 0.09 & 0.09 \\
RSD & 1.0 & 1.0 \\
Lakewater $(\mathrm{nM})$ & $9.67 \pm 0.02$ & $9.64 \pm 0.04$ \\
SD & 0.08 & 0.07 \\
RSD & 0.8 & 0.7 \\
${ }^{a} \bar{X}$ : mean \pm standard error, SD: standard deviation, RSD: $\%$ relative \\
standard deviation.
\end{tabular}



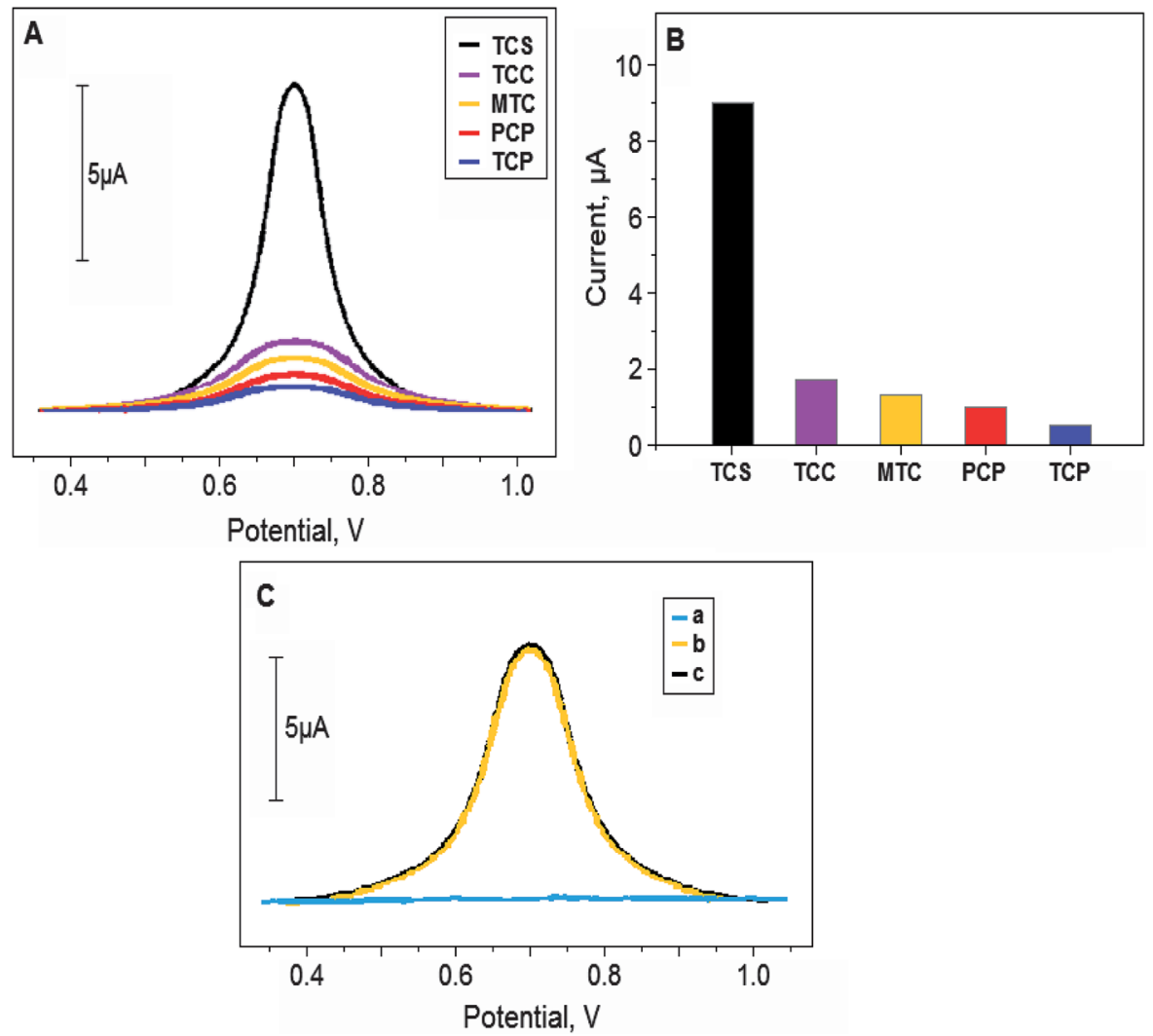

Fig. 7 (A) DPVs of imprinted electrochemical sensor towards $15.0 \mathrm{nM}$ TCS, TCC, MTC, PCP and TCP. (B) The values of peak current of TCS, TCC, MTC, PCP and TCP. (C) DPVs of imprinted electrochemical sensor towards (a) blank solution, (b) $15.0 \mathrm{nM}$ standard TCS solution and (c) wastewater sample containing $15.0 \mathrm{nM}$ TCS.

Table 3 Comparison of the performances of different methods for TCS analysis

\begin{tabular}{lll}
\hline Method & Linear range & LOD \\
\hline Improved electro-oxidation & $5.1 \times 10^{-9}$ to $6.9 \times 10^{-6} \mathrm{~mol} \mathrm{~L}^{-1}$ & $4.5 \times 10^{-9} \mathrm{~mol} \mathrm{~L}^{-1}$ \\
UV-Vis micro-spectrophotometry & $4.8 \times 10^{-8}$ to $5.9 \times 10^{-6} \mathrm{~mol} \mathrm{~L}^{-1}$ & $3.0 \times 10^{-9} \mathrm{~mol} \mathrm{~L}^{-1}$ \\
Spectrophotometry & 0 to $1.0 \times 10^{-4} \mathrm{~mol} \mathrm{~L}^{-1}$ & $2.7 \times 10^{-4} \mathrm{~mol} \mathrm{~L}^{-1}$ \\
Voltammetric & $8.6 \times 10^{-9}$ to $2.0 \times 10^{-7} \mathrm{~mol} \mathrm{~L}^{-1}$ & $6.5 \times 10^{-9} \mathrm{~mol} \mathrm{~L}^{-1}$ \\
HPLC & $2.7 \times 10^{-8}$ to $2.0 \times 10^{-7} \mathrm{~mol} \mathrm{~L}^{-1}$ & $6.9 \times 10^{-9} \mathrm{~mol} \mathrm{~L}^{-1}$ \\
ISE/MIP & $1.0 \times 10^{-8}$ to $1.0 \times 10^{-5} \mathrm{~mol} \mathrm{~L}^{-1}$ & $1.9 \times 10^{-9} \mathrm{~mol} \mathrm{~L}^{-1}$ \\
CNTs@TCS-MIP & $3.4 \times 10^{-9}$ to $1.4 \times 10^{-7} \mathrm{~mol} \mathrm{~L}^{-1}$ & $3.4 \times 10^{-9} \mathrm{~mol} \mathrm{~L}^{-1}$ \\
MIP/amperometric & $2.0 \times 10^{-7}$ to $3.0 \times 10^{-6} \mathrm{~mol} \mathrm{~L}^{-1}$ & $8.0 \times 10^{-8} \mathrm{~mol} \mathrm{~L}^{-1}$ \\
MIP/AuNPs/POM/rGO & $5.1 \times 10^{-10}$ to $5.0 \times 10^{-8} \mathrm{~mol} \mathrm{~L}^{-1}$ & $1.5 \times 10^{-10} \mathrm{~mol} \mathrm{~L}^{-1}$
\end{tabular}

TCS (Fig. 7C). Thus, we produced a highly selective sensor via creating binding sites that are specific to the target molecule.

For reproducibility study, six different MIP/AuNPs/POM/ rGO/GC electrodes were prepared under the same condition and tested in TCS detection and analysis. After that, each MIP electrode was applied to wastewater samples for TCS analysis. According to the obtained results, the relative standard deviation (RSD) is $0.3 \%$ in $10.0 \mathrm{nM}$ TCS.

The stability of MIP/AuNPs/POM/rGO/GC electrode was also checked. After 30 days, the signal was found to be approximate $98.8 \%$ of the original value which suggests its excellent longterm stability. Table 3 presents a comparison of the sensor performance in terms of linear range and LOD with other analytical methods. It is seen that the developed sensor showed a much lower limit of detection.

\section{Conclusion}

A new TCS imprinted electrochemical sensor based on AuNPs/ $\mathrm{POM} / \mathrm{rGO}$ modified GC electrode was prepared and tested for determination of trace TCS in aqueous solution. The prepared sensor exhibits high selectivity and sensitivity in TCS detection with a detection limit of $0.15 \mathrm{nM}$. It demonstrates analytic capability comparable to other complicated methods but it offers simple and efficient application in target detection from wastewater and lakewater samples. 


\section{Acknowledgements}

We thank the Australia Research Council for partially financial support under Project No. DP150103026.

\section{References}

1 M. Moyo, L. R. Florence and J. O. Okonkwo, Sens. Actuators, $B, 2015,209,898-905$.

2 X. Zhu, Y. Liu, G. Luo, F. Qian, S. Zhang and J. Chen, Environ. Sci. Technol., 2014, 48, 5840-5848.

3 P. Canosa, I. Rodríguez, E. Rubí and R. Cela, Anal. Chem., 2007, 79, 1675-1681.

4 L. Vidal, A. Chisvert, A. Canals, E. Psillakis, A. Lapkin, F. Acosta, K. J. Edler, J. A. Holdaway and F. Marken, Anal. Chim. Acta, 2008, 616, 28-35.

5 Y. Liu, Q.-J. Song and L. Wang, Microchem. J., 2009, 91, 222226.

6 J.-L. Wu, N. P. Lam, D. Martens, A. Kettrup and Z. Cai, Talanta, 2007, 72, 1650-1654.

7 H. T. Rasmussen, R. McDonough, R. J. Gargiullo and B. P. McPherson, J. High Resolut. Chromatogr., 1996, 19, 359-361.

8 S. Chu and C. D. Metcalfe, J. Chromatogr. A, 2007, 1164, 212218.

9 M. J. Bonné, K. J. Edler, J. G. Buchanan, D. Wolverson, E. Psillakis, M. Helton, W. Thielemans and F. Marken, J. Phys. Chem. C, 2008, 112, 2660-2666.

10 M. A. Coogan, R. E. Edziyie, T. W. La Point and B. J. Venables, Chemosphere, 2007, 67, 1911-1918.

11 M. L. Yola, T. Eren and N. Atar, Sens. Actuators, B, 2015, 210, 149-157.

12 H. Karimi-Maleh, F. Tahernejad-Javazmi, A. A. Ensafi, R. Moradi, S. Mallakpour and H. Beitollahi, Biosens. Bioelectron., 2014, 60, 1-7.

13 M. L. Yola, L. Uzun, N. Özaltın and A. Denizli, Talanta, 2014, 120, 318-324.

14 V. K. Gupta, M. L. Yola, N. Atar, Z. Üstündağ and A. O. Solak, J. Mol. Liq., 2014, 191, 172-176.

15 M. L. Yola, T. Eren and N. Atar, Sens. Actuators, B, 2014, 195, 28-35.

16 W. Gu, X. Deng, X. Gu, X. Jia, B. Lou, X. Zhang, J. Li and E. Wang, Anal. Chem., 2015, 87, 1876-1881.
17 K. Kume, N. Kawasaki, H. Wang, T. Yamada, H. Yoshikawa and K. Awaga, J. Mater. Chem. A, 2014, 2, 3801-3807.

18 G. Eda and M. Chhowalla, ACS Nano, 2011, 5, 4265-4268.

19 S. Mao, H. Pu and J. Chen, RSC Adv., 2012, 2, 2643-2662.

20 S. Liu, W. Peng, H. Sun and S. Wang, Nanoscale, 2014, 6, 766771.

21 Y. Yao, Y. Cai, F. Lu, F. Wei, X. Wang and S. Wang, J. Hazard. Mater., 2014, 270, 61-70.

22 Y. Yao, C. Xu, J. Qin, F. Wei, M. Rao and S. Wang, Ind. Eng. Chem. Res., 2013, 52, 17341-17350.

23 H. Karimi-Maleh, M. Moazampour, V. K. Gupta and A. L. Sanati, Sens. Actuators, B, 2014, 199, 47-53.

24 M. L. Yola, N. Atar and T. Eren, Sens. Actuators, B, 2014, 198, 70-76.

25 M. L. Yola, T. Eren, N. Atar and S. Wang, Chem. Eng. J., 2014, 242, 333-340.

26 K. Novoselov, Nat. Mater., 2007, 6, 720-721.

27 M. L. Yola, T. Eren and N. Atar, Biosens. Bioelectron., 2014, 60, 277-285.

28 Y. Kim and S. Shanmugam, ACS Appl. Mater. Interfaces, 2013, 5, 12197-12204.

29 R. Liu, S. Li, X. Yu, G. Zhang, S. Zhang, J. Yao and L. Zhi, J. Mater. Chem., 2012, 22, 3319-3322.

30 V. K. Gupta, M. L. Yola and N. Atar, Sens. Actuators, B, 2014, 194, 79-85.

31 B. Jiang, Y. Liang, Q. Wu, H. Jiang, K. Yang, L. Zhang, Z. Liang, X. Peng and Y. Zhang, Nanoscale, 2014, 6, 56165619.

32 S. Li, X. Yu, G. Zhang, Y. Ma, J. Yao and P. de Oliveira, Carbon, 2011, 49, 1906-1911.

33 N. Cabaleiro, F. Pena-Pereira, I. de la Calle, C. Bendicho and I. Lavilla, Microchem. J., 2011, 99, 246-251.

34 H. Lu, H. Ma and G. Tao, Spectrochim. Acta, Part A, 2009, 73, 854-857.

35 A. Safavi, N. Maleki and H. R. Shahbaazi, Anal. Chim. Acta, 2003, 494, 225-233.

36 A. Piccoli, J. Fiori, V. Andrisano and M. Orioli, Farmaco, 2002, 57, 369-372.

37 R. Liang, L. Kou, Z. Chen and W. Qin, Sens. Actuators, B, 2013, 188, 972-977.

38 R. Gao, X. Kong, F. Su, X. He, L. Chen and Y. Zhang, J. Chromatogr. A, 2010, 1217, 8095-8102. 